Claremont Colleges

Scholarship@ Claremont

CMC Faculty Publications and Research

CMC Faculty Scholarship

4-1-2004

\title{
The Changing Nature of Employment-Related Sexual Harassment: Evidence from the U.S. Federal Government, 1978 - 1994
}

Heather Antecol

Claremont McKenna College

Deborah Cobb-Clark

\section{Recommended Citation}

Antecol, Heather, and Deborah Cobb-Clark. "The Changing Nature of Employment-Related Sexual Harassment: Evidence from the U.S. Federal Government, 1978 - 1994." Industrial and Labor Relations Review 57.3 (2004): 443-461.

This Article is brought to you for free and open access by the CMC Faculty Scholarship at Scholarship @ Claremont. It has been accepted for inclusion in CMC Faculty Publications and Research by an authorized administrator of Scholarship @ Claremont. For more information, please contact scholarship@cuc.claremont.edu. 


\section{ILRReview}

Volume 57 | Number 3

2004

The Changing Nature of Employment-Related Sexual Harassment: Evidence from the U.S. Federal Government, 1978-1994

Heather Antecol

Claremont McKenna College

Deborah Cobb-Clark

Australian National University 


\title{
The Changing Nature of Employment-Related Sexual Harassment: Evidence from the U.S. Federal Government, 1978-1994
}

\begin{abstract}
This paper examines the changing nature of attitudes toward and reports of sexual harassment using data for 1978-94 drawn from the U.S. Merit Systems Protection Board (USMSPB) of the U.S. federal government. The authors find that although unwanted sexual behavior reported by federal government employees changed only slightly in overall incidence over the period, its pattern changed noticeably. Unwanted sexual attention by supervisors, for example, declined in incidence; crude and offensive behavior by co-workers increased; and the likelihood that harassment would occur only once (rather than repeatedly) increased. Employees' attitudes toward sexual harassment changed markedly, with a dramatically increased willingness to define unwanted sexual behavior as sexual harassment. This trend appears to have been due not to changes in employees' demographic, human capital, and job characteristics, but rather to structural changes in their views of what constitutes sexual harassment.
\end{abstract}




\title{
THE CHANGING NATURE OF EMPLOYMENT- RELATED SEXUAL HARASSMENT: EVIDENCE FROM THE U.S. FEDERAL GOVERNMENT, 1978-1994
}

\author{
HEATHER ANTECOL and DEBORAH COBB-CLARK*
}

\begin{abstract}
This paper examines the changing nature of attitudes toward and reports of sexual harassment using data for 1978-94 drawn from the U.S. Merit Systems Protection Board (USMSPB) of the U.S. federal government. The authors find that although unwanted sexual behavior reported by federal government employees changed only slightly in overall incidence over the period, its pattern changed noticeably. Unwanted sexual attention by supervisors, for example, declined in incidence; crude and offensive behavior by co-workers increased; and the likelihood that harassment would occur only once (rather than repeatedly) increased. Employees' attitudes toward sexual harassment changed markedly, with a dramatically increased willingness to define unwanted sexual behavior as sexual harassment. This trend appears to have been due not to changes in employees' demographic, human capital, and job characteristics, but rather to structural changes in their views of what constitutes sexual harassment.
\end{abstract}

$\mathbf{S}$ exual harassment is a fact of life for many working women, with some studies suggesting that work-related sexual harassment may affect as many as one in two women at some point in their work lives (Schneider et al. 1997; Fitzgerald and Omerod 1993). The International Labour Organization (ILO), for example, recently reviewed the international literature and concluded that "sexual harassment is a pervasive problem affecting substantial numbers of women in every industrialized country where information is available" (ILO 1992). Sexual harassment is increasingly

*Heather Antecol is an assistant professor of Economics at Claremont McKenna College, and Deborah Cobb-Clark is Director of the Social Policy Evaluation, Analysis and Research Centre at the Australian National University. being recognized as an important economic issue in large part because of the substantial costs it imposes on workers and their employers.

In spite of its pervasiveness, sexual harassment is not easy to define or measure. Many authors have suggested that the term "sexual harassment" is simply a new name for an old problem (ILO 1992; Fitzgerald and Shullman 1993), ${ }^{1}$ and despite the growing research, there is still no commonly accepted definition of sexual harassment

A data appendix with additional results, and copies of the computer programs used to generate the results presented in the paper, are available from the first author at Claremont McKenna College, Dept. of Economics, 500 E. Ninth Street, Claremont, CA 91711.

${ }^{1}$ Fitzgerald and Shullman (1993) described sexual harassment as "a social problem with a long past and a short history." 
(Roscoe et al. 1994; Foulis and McCabe 1997). The existing evidence is often based on small, non-representative samples of women, hampering direct comparisons across studies (Fitzgerald and Shullman 1993). While some patterns in the factors associated with sexual harassment are beginning to emerge, we know almost nothing about how these patterns have changed over time as public awareness of sexual harassment has grown. The dearth of widely accepted stylized facts-along with a lack of agreement about how to define and measure sexual harassment-makes it difficult to address the problem and find solutions.

This paper fills a void in the literature by using data for 1978-94 drawn from the U.S. Merit Systems Protection Board (USMSPB) of the U.S. federal government to examine the changing nature of sexual harassment. We focus on two dimensions of sexual harassment: the incidence of various unwanted sexual behaviors, and individuals' views about what behaviors in fact constitute sexual harassment. Understanding workers' perceptions of sexual behavior at work is especially important given a legal environment that relies on a reasonable victim standard-increasingly a reasonable woman standard-to make determinations in sexual harassment cases (Prior et al. 1997; Fitzgerald and Shullman 1993) ${ }^{2}$ and evidence that the negative consequences of unwanted sexual behavior at work are higher for women who believe themselves to be sexually harassed than for those who report unwanted sexual behavior but do not characterize it as harassment (Antecol and Cobb-Clark 2002).

We are particularly interested in the following questions. To the extent that the incidence and definition of sexual harassment varied between 1978 and 1994, what drove this change? Was it a natural consequence of the altered demographic com-

${ }^{2}$ In particular, Equal Employment Opportunity Commission (EEOC) guidelines issued in 1980 emphasized that sexual harassment is unwelcome sexual behavior (emphasis added; Prior et al. 1997). position of the workplace that resulted from the expansion in employment opportunities for women? Or did it, rather, result from a change in the propensity-conditional on one's characteristics-to experience unwanted sexual behaviors and label them as sexual harassment? Our goal is to answer these questions using standard decomposition and regression techniques that can identify the source of changes in sexual harassment over time. This-in combination with information about the qualitative nature of sexual harassment-sheds light on potential explanations for any structural shift in employment-related sexual harassment.

\section{Employment-Related Sexual Harassment: Evidence and Issues}

Sexual harassment cases first appeared in U.S. courts in the early 1970 s when it was argued that sexual harassment constituted a form of gender-based discrimination. Since that time, public awareness of the issue has grown in large part due to certain well-publicized legal cases (Prior et al. 1997). To date, the study of employmentrelated sexual harassment has been mainly the purview of psychologists and sociologists. Economists have generally had relatively little to say about the matter. In particular, although several theoretical models of labor market discrimination exist in the economics literature, corresponding models of sexual harassment are notoriously absent. ${ }^{3}$

Most empirical research is based on surveys of selected workers, or, in some cases, university students. The small, non-representative nature of many of the samples used in these studies, as well as differences in survey design, methodology, and the way in which sexual harassment is measured, make synthesis of the results difficult. None-

\footnotetext{
${ }^{3}$ The exception is Basu (2002), who modeled the circumstances under which it is Pareto improving to ban sexual harassment even though workers would find the pay attractive enough to submit to it.
} 
theless, several broad conclusions can be drawn from the existing literature. First, reports of sexual harassment are common across a number of employment situations in a number of countries. In particular, the U.S. evidence points to a high incidence of sexual harassment for women employed in a range of settings, including the military, large private-sector organizations, universities, legal practice, and the federal government (Antecol and Cobb-Clark 2002; Schneider et al. 1997; Laband and Lentz 1998; USMSPB 1995); and international research documents a high incidence of sexual harassment in many other countries around the world (Johnson 1994; ILO 1992).

The incidence of sexual harassment is related both to demographic characteristics and to the nature of one's employment. Women experience more sexual harassment than do men (see, for example, Fitzgerald and Ormerod 1993; Antecol and Cobb-Clark 2001), although many men also experience employment-related sexual harassment, and there is evidence that harassment of men is growing (USMSPB 1981, 1988, 1995). Victims of sexual harassment are also more likely than non-victims to be relatively young, to be unmarried, to have attended college, and to work exclusively with and be supervised by members of the opposite sex (see Fitzgerald et al. 1999b; Schneider et al. 1997; Laband and Lentz 1998; USMSPB 1995; Antecol and Cobb-Clark 2001). Organizational factors can also facilitate or inhibit sexual harassment (Williams et al. 1999). Women in the U.S. military, for example, report less sexual harassment when their duty stations have sexual harassment hotlines, offices devoted to investigating sexual harassment reports, and formal complaint procedures, or when they themselves have received sexual harassment training (Antecol and Cobb-Clark 2002).

It is also important to note that while many workers say they have experienced unwanted sexual behavior, they often do not label their experiences as sexual harassment per se (see Antecol and CobbClark 2001; Marin and Guadagno 1999; Magley et al. 1999). Though the empirical evidence is limited, women appear more likely to apply the sexual harassment label when the behavior is more severe or when the gender mix in the work environment is not equal (Antecol and Cobb-Clark 2001). However, sexual harassment often goes unreported. Less than $5 \%$ of individuals experiencing sexual harassment ever report their experiences to anyone in authority, and even fewer file formal complaints with employers, institutions, or legal authorities (see Marin and Guadagno 1999 and Fitzgerald and Shullman 1993).

Sexual harassment is particularly troubling in light of the mounting evidence that it has negative consequences for workers, including increased job turnover, higher absenteeism, reduced job satisfaction, lower productivity, and adverse health outcomes. ${ }^{4}$ Sexual harassment on the job also imposes sizable costs on firms. Between 1992 and 1994 sexual harassment is estimated to have cost the federal government \$327 million (USMSPB 1995), and a study of 160 major U.S. firms found that sexual harassment costs each firm $\$ 6.7$ million per year (not including the legal costs associated with defending such actions) (ILO 1992).

The U.S. federal government makes an especially interesting setting in which to study employment-related sexual harassment. There has been a large expansion of female employment within the U.S. federal government-from $33 \%$ in 1978 to $44 \%$ in 1994 (U.S. Bureau of the Census 1980; USOPM 1999). Lewis (1996) reported that much of this expansion has occurred within traditionally male-dominated occupations-in particular, professional and administrative occupations-leading the gender integration of occupations to be much

\footnotetext{
${ }^{4}$ See Schneider et al. (1997), Fitzgerald et al. (1997), and Marin and Guadagno (1999) for reviews of the psychology literature regarding the consequences of sexual harassment. A small economics literature also examines the effect of sexual harassment on job satisfaction and intentions to quit (Laband and Lentz 1998; Antecol and Cobb-Clark 2002).
} 
more rapid in the federal government than in the general economy. For example, in 1977 , the average male federal government employee worked in an occupation that was approximately $78 \%$ male, whereas by 1993 this had fallen to $68 \%$. The implications of these employment trends for sexual harassment are likely to be complicated. On the one hand, women have made rapid progress up the federal government's occupational ladder, leaving many of them in high-level, supervisory positions and increasing their ability to influence institutional culture. ${ }^{5}$ At the same time, men and women are increasingly working together, which may increase the incidence of unwanted sexual behavior on the job.

\section{U.S. Merit Systems Protection Board Data}

We use data drawn from the U.S. Merit Systems Protection Board (USMSPB) of the U.S. federal government for 1978, 1987, and 1994. These data are uniquely suited to the analysis at hand. First, they provide us with fifteen years of comparable, consistently defined data on men's and women's experiences of and attitudes toward unwanted sexual behavior in the workplace. ${ }^{6}$ Additionally, whereas much of the existing employment-related sexual harassment literature is based on relatively small samples of workers in selected occupations (such as lawyers or academics), specific age groups (such as university students), or single firms, the USMSPB data set is large and encompasses public-sector workers employed in a range of occupations across all agencies of the federal government.

\footnotetext{
${ }^{5}$ Both supervisor's gender and the gender composition of the work force are important determinants of the likelihood of being sexually harassed (USMSPB 1995; Fitzgerald et al. 1999b).

${ }^{6}$ We are aware of no other source of consistent data on sexual harassment spanning a similar time period. While cross-sectional analyses of USMSPB data exist (USMSPB 1981, 1988, 1995), these data have not been used to analyze the source of changes in sexual harassment over time.
}

In each of these years, a non-proportional, stratified sample of civilian employees was randomly drawn from the Central Personnel Data File (CPDF) operated by the U.S. Office of Personnel Management $(\mathrm{OPM}) .^{7}$ Data were stratified on the basis of gender, agency, salary, and (in 1978 only) minority status. From an initial sample of 23,964 individuals in 1978, usable questionnaires were returned from 20,083 individuals, for an overall response rate of $84 \%$ (USMSPB 1981). In 1987 and 1994 the overall response rates were lower, with usable questionnaires returned from 8,523 and 8,081 individuals in those years respectively, for overall response rates of $66 \%$ and $61 \%$ (USMSPB 1988, 1995). Our final sample consists of 16,408 (1978), 7,487 (1987), and 5,875 (1994) civilian employees with non-missing values for the variables of interest. ${ }^{8}$

USMSPB respondents were asked whether they had experienced one or more of seven unwanted sexual behaviors on the job in the previous 24 months: (1) sexual gestures, (2) sexual remarks, (3) sexual materials, (4) pressure for sexual favors, (5) deliberate touching, (6) pressure for dates, and (7) sexual assault. Allowed responses include "never," "once," "once a month or less," "two to four times a month," and "once a week or more." As our interest is in sexual harassment, we omit consideration of category (7). ${ }^{9}$ Our first step was to construct an indicator variable for each type of unwanted sexual behavior that

\footnotetext{
${ }^{7}$ Some agencies-for example, the Central Intelligence Agency-are not required to report personnel information to the OPM. Therefore, civilian employees from these agencies are not included in the sample frame. For a list of excluded agencies, see USMSPB (1981, 1988, and 1995).

${ }^{8}$ Though the response rate is lower in the latter two years, the respondents were a representative crosssection of federal employees. Moreover, the latter two surveys were developed in part to examine the trends in sexual harassment in the federal government. For a more detailed discussion, see USMSPB (1988, 1995)

${ }^{9}$ Sexual assault involves rape or attempted rape and is not usually considered sexual harassment per se.
} 
equals 1 if the respondent reported experiencing the behavior at least once, and 0 otherwise. Second, we aggregated the responses to items $(1)-(6)$ into three broad types of sexually harassing behavior: crude or offensive behavior (sexual gestures, sexual remarks, and sexual materials), unwanted sexual attention (pressure for sexual favors, deliberate touching, and pressure for dates), and any unwanted sexual behavior. Thus, following standard practice in this literature, our notion of sexual harassment is based on one or more experiences of unwanted sexual behavior. It does not rely on individuals reporting themselves to have been "sexually harassed" and does not necessarily fit with legal definitions. ${ }^{10}$

Respondents were also asked whether they would consider six separate unwanted sexual behaviors (specifically, sexual gestures, sexual remarks, sexual materials, pressure for sexual favors, deliberate touching, and pressure for dates) initiated by a supervisor to be sexual harassment. Identical questions were then asked about those same six behaviors initiated by a co-worker. Allowable responses include "definitely not," "probably not," "don't know," "probably yes," and "definitely yes." We constructed an indicator variable $\left(Y_{i t}\right)$ for each of these twelve outcomes that equals 1 if respondent $i$ reported in year $t$ that he or she "probably" or "definitely" would consider that specific behavior to be sexual harassment and equals 0 otherwise.

The reported incidence of unwanted sexual behavior and views about what constitutes sexual harassment are shown in Table 1. Not surprisingly, women were

\footnotetext{
${ }^{10}$ In particular, Fitzgerald et al. (1999a) argued that since without a judicial procedure it is impossible to determine who would meet legal criteria, a legal definition would be impractical for most research and policy purposes. Definitions based on the filing of a sexual harassment complaint are also flawed because sexual harassment often goes unreported, while definitions based on one's perception of having been harassed introduce an element of subjectivity into the analysis (see also USMSPB 1995.)
}

more likely than men to consider various unwanted sexual behaviors to be sexual harassment, regardless of the year. ${ }^{11}$ Further, the proportion of men and women who would view unwanted sexual behavior to be sexual harassment increased dramatically over time. For example, $91 \%$ of women in 1994 would have considered unwanted pressure for dates to be sexual harassment if initiated by a supervisor, compared to only $78 \%$ of women in 1978 .

Women were also more likely than men to report experiencing unwanted sexual behavior. In 1987, $41 \%$ of women reported experiencing any unwanted sexual behavior, compared with $15 \%$ of men. The most frequently reported form of unwanted sexual behavior was unwanted sexual remarks, while unwanted pressure for sexual favors was least common. Interestingly, the change over time in reported sexual harassment experiences is much smaller than the change over time in views about what constitutes sexual harassment. For example, the incidence of unwanted sexual gestures increased by 1.3 (1.2) percentage points for women (men) between 1978 and 1994, while the proportion of employees who would have considered unwanted sexual gestures from supervisors to be sexual harassment increased by 19.4 (18.2) percentage points for women (men) between 1978 and $1994 .{ }^{12}$

\section{The Role of the Changing Composition of the Federal Work Force}

We can shed further light on these trends by assessing whether they can be explained by the changing composition of the federal work force. To this end, we analyze the twelve indicator variables $\left(Y_{i t}\right)$ reflecting respondents' attitudes about sexual harassment (see Table 1). The incidence of un-

\footnotetext{
${ }^{11}$ This is consistent with evidence that women see a wide range of behaviors as "harassing" (Fitzgerald and Shullman 1993), though the gender gap is generally smaller for more severe behaviors (Prior et al. 1997).

${ }^{12}$ USMSPB data also include demographic, human capital, and job information. See Appendix Table A1.
} 
Table 1. Reports of Attitudes toward and

Incidence of Unwanted Sexual Behavior by Gender and Year.

\begin{tabular}{|c|c|c|c|c|c|c|}
\hline \multirow[b]{3}{*}{ Behavior } & \multicolumn{6}{|c|}{ Proportion Reporting } \\
\hline & \multicolumn{3}{|c|}{ Women } & \multicolumn{3}{|c|}{ Men } \\
\hline & 1978 & 1987 & 1994 & 1978 & 1987 & 1994 \\
\hline \multicolumn{7}{|c|}{ Panel A: Attitudes toward Sexual Harassment } \\
\hline \multicolumn{7}{|c|}{ Considered Sexual Harassment If Supervisor Did the Following: } \\
\hline Unwanted Sexual Gestures & 0.715 & 0.813 & 0.909 & 0.591 & 0.679 & 0.773 \\
\hline Unwanted Sexual Remarks & 0.615 & 0.714 & 0.829 & 0.528 & 0.575 & 0.726 \\
\hline Unwanted Sexual Materials & 0.934 & 0.897 & 0.946 & 0.872 & 0.763 & 0.882 \\
\hline Unwanted Pressure for Sexual Favors & 0.916 & 0.987 & 0.991 & 0.843 & 0.959 & 0.971 \\
\hline Unwanted Deliberate Touching & 0.905 & 0.949 & 0.981 & 0.831 & 0.889 & 0.933 \\
\hline Unwanted Pressure for Dates & 0.775 & 0.862 & 0.913 & 0.756 & 0.813 & 0.857 \\
\hline \multicolumn{7}{|c|}{ Considered Sexual Harassment If Co-Worker Did the Following: } \\
\hline Unwanted Sexual Gestures & 0.635 & 0.761 & 0.882 & 0.466 & 0.591 & 0.703 \\
\hline Unwanted Sexual Remarks & 0.531 & 0.634 & 0.761 & 0.414 & 0.463 & 0.636 \\
\hline Unwanted Sexual Materials & 0.875 & 0.840 & 0.915 & 0.758 & 0.671 & 0.816 \\
\hline Unwanted Pressure for Sexual Favors & 0.811 & 0.976 & 0.980 & 0.648 & 0.903 & 0.928 \\
\hline Unwanted Deliberate Touching & 0.839 & 0.920 & 0.962 & 0.690 & 0.823 & 0.892 \\
\hline Unwanted Pressure for Dates & 0.649 & 0.758 & 0.849 & 0.585 & 0.663 & 0.751 \\
\hline \multicolumn{7}{|c|}{ Panel B: Reported Sexual Harassment } \\
\hline Any Behavior & 0.410 & 0.412 & 0.454 & 0.137 & 0.145 & 0.193 \\
\hline Crude/Offensive Behavior & 0.374 & 0.385 & 0.422 & 0.125 & 0.132 & 0.170 \\
\hline Unwanted Sexual Gestures & 0.275 & 0.275 & 0.288 & 0.075 & 0.083 & 0.087 \\
\hline Unwanted Sexual Remarks & 0.323 & 0.339 & 0.375 & 0.096 & 0.111 & 0.137 \\
\hline Unwanted Sexual Materials & 0.080 & 0.117 & 0.102 & 0.028 & 0.042 & 0.038 \\
\hline Unwanted Sexual Attention & 0.304 & 0.294 & 0.278 & 0.078 & 0.091 & 0.096 \\
\hline Unwanted Pressure for Sexual Favors & 0.090 & 0.084 & 0.071 & 0.022 & 0.028 & 0.023 \\
\hline Unwanted Deliberate Touching & 0.257 & 0.255 & 0.236 & 0.062 & 0.073 & 0.082 \\
\hline Unwanted Pressure for Dates & 0.142 & 0.142 & 0.124 & 0.027 & 0.039 & 0.031 \\
\hline Number of Observations & 8,692 & 3,926 & 3,198 & 7,716 & 3,561 & 2,677 \\
\hline
\end{tabular}

Note: Sampling weights used.

wanted sexual behaviors is captured by two of our broad measures of sexually harassing behavior: "any unwanted behavior" and "unwanted sexual attention" (see Table 1). This parameterization accounts to a degree for the severity of sexual harassment.

The probability of viewing behavior $j$ to be sexual harassment or experiencing unwanted sexual behavior is given by

(1) $\operatorname{Pr}\left(Y_{i t}^{j}=1\right)=\operatorname{Pr}\left(X_{i} \beta+\varepsilon_{i t}>0\right)=\Phi\left(X_{i} \beta\right)$, where $j$ indexes our 14 outcomes of interest and $\Phi$ is the standard normal cumulative density function. Equation (1) is estimated separately by gender and year using a probit model. ${ }^{13}$ The change between years $t-1$ and $t$ in the expected probability of viewing a specific behavior as sexual harassment or in experiencing unwanted sexual behavior $\left(\hat{Y}^{j}\right)$ can then be approximated by

$$
\begin{gathered}
\hat{Y}_{t}^{j}-\hat{Y}_{t-1}^{j} \cong \Phi\left(\bar{X} \hat{\beta}_{t}\right)-\Phi\left(\bar{X}_{t-1} \hat{\beta}_{t-1}\right) \\
\cong\left[\Phi\left(\bar{X}_{t} \hat{\beta}_{t}\right)-\Phi\left(\bar{X}_{t} \hat{\beta}_{t-1}\right)\right]+\left[\Phi\left(\bar{X}_{t} \hat{\beta}_{t-1}\right)\right. \\
\left.-\Phi\left(\bar{X}_{t-1} \hat{\beta}_{t-1}\right)\right],
\end{gathered}
$$

\footnotetext{
${ }^{13}$ All estimation was conducted in STATA 7.0. Independent variables in the model include age, education, marital status, occupation, pay grade, and the gender of one's supervisor.
} 
where $\Phi\left(\bar{X}_{t} \hat{\beta}_{t-1}\right)$ is an estimate of the (counterfactual) probability that would result if workers had period $t$ characteristics but responded like individuals in period $t-1 .{ }^{14}$ The first right-hand-side term in equation (2) captures the component of the change over time that is due to changes in the coefficients, and the second term captures the component that is due to changes in demographic, human capital, and job characteristics of federal government employees.

Results of the decomposition given by equation (2) - and the alternative decomposition based on $\Phi\left(\bar{X}_{t-1} \hat{\beta}_{t}\right)$-indicate that very little of the change over time in the probability of viewing unwanted sexual behavior as sexual harassment can be explained by changes in the distribution of workers' demographic, human capital, and job characteristics (see Panel A of Table 2). Most of the increase results from structural change, that is, changes in the propensity of men and women (conditional on their characteristics) to view the behavior as sexual harassment. ${ }^{15}$ In 1978, for example, $71.5 \%$ of women responded that they would view unwanted sexual gestures by a supervisor as sexual harassment, compared to $81.3 \%$ in 1987 (see Table 1). If women had retained their 1978 characteristics, but responded as women did in 1987, fully $80.3 \%$ would have included unwanted sexual gestures by a supervisor in their definition of sexual harassment (see Panel A of Table 2). Thus, when 1987 coefficients are used as weights, only $10.4 \%$ of the overall change in women's views is explained by changes in their human capital and job characteristics. When 1978 coefficients are used as weights, none of the change is explained by changing characteristics.

\footnotetext{
${ }^{14}$ The approximation is due to the nonlinear form of the standard normal cumulative distribution (see Doiron and Riddell 1994). Linear probability results are similar and are available upon request.

${ }^{15}$ This conclusion is also supported by structural change tests that formally assess whether determinants have changed over time. These results are available upon request.
}

Regardless of the decomposition used, changes in the distribution of demographic, human capital, and job characteristics between 1978 and 1987 account for at most $10 \%$ of the total change in men's and women's views toward what constitutes sexual harassment. Although changing characteristics explain more of the increased willingness to apply the sexual harassment label between 1987 and 1994, particularly for women, by and large the change in sexual harassment definitions cannot be explained by the changing composition of the federal work force.

At first glance, changes in the demographic composition of the work force appear to explain more of the change in the incidence of unwanted sexual behavior on the job (see Panel B of Table 2). However, the underlying change in the incidence of unwanted sexual behavior itself is often quite small-particularly between 1978 and 1987-making the decomposition results somewhat sensitive to the choice of weight and not as informative. The exception is the relatively large increase in the propensity of men (4.8 percentage points) and women (4.2 percentage points) to report any unwanted behavior between 1987 and 1994 (see Table 1). In this case, the timetrend also appears to be largely unexplained by changes in the demographic, human capital, and job characteristics of workers.

\section{The Source of Changes in Views toward and Incidence of Sexual Harassment}

The decomposition analysis highlights the importance of structural changes in the propensity of individuals to define certain unwanted sexual behaviors as sexual harassment, raising many questions regarding the specific nature of these changes. In particular, have federal government workers generally altered their views, or have changes been concentrated among certain employee groups? Did changes occur uniformly over time, or were they concentrated in one or more periods? Answers to these questions may be useful for evaluating potential explanations for these trends and may shed light on strategies for better targeting of policies to combat sexual harassment. 
Table 2. Predicted Probabilities of Various Attitudes toward and Measures of Reported Sexual Harassment by Gender.

\begin{tabular}{|c|c|c|c|c|c|c|}
\hline \multirow[b]{2}{*}{ Description } & & \multicolumn{2}{|c|}{$1978-1987$} & & \multicolumn{2}{|c|}{$1987-1994$} \\
\hline & & Women & Men & & Women & Men \\
\hline & \multicolumn{6}{|c|}{ Panel A: Attitudes toward Sexual Harassment } \\
\hline \multicolumn{7}{|c|}{ Unwanted Sexual Gestures } \\
\hline \multirow[t]{2}{*}{ Supervisor } & x87b78 & 0.715 & 0.592 & x94b87 & 0.830 & 0.682 \\
\hline & $\mathrm{x} 78 \mathrm{~b} 87$ & 0.803 & 0.675 & x87b94 & 0.895 & 0.768 \\
\hline \multirow[t]{2}{*}{ Co-Worker } & $\mathrm{x} 87 \mathrm{~b} 78$ & 0.634 & 0.468 & $\mathrm{x} 94 \mathrm{~b} 87$ & 0.773 & 0.583 \\
\hline & $\mathrm{x} 78 \mathrm{~b} 87$ & 0.750 & 0.589 & x87b94 & 0.870 & 0.697 \\
\hline \multicolumn{7}{|c|}{ Unwanted Sexual Remarks } \\
\hline \multirow[t]{2}{*}{ Supervisor } & x $87 b 78$ & 0.609 & 0.532 & x94b87 & 0.729 & 0.591 \\
\hline & x78b87 & 0.707 & 0.572 & x87b94 & 0.818 & 0.722 \\
\hline \multirow[t]{2}{*}{ Co-Worker } & $\mathrm{x} 87 \mathrm{~b} 78$ & 0.525 & 0.417 & x94b87 & 0.645 & 0.469 \\
\hline & $\mathrm{x} 78 \mathrm{~b} 87$ & 0.624 & 0.459 & x87b94 & 0.756 & 0.631 \\
\hline \multicolumn{7}{|c|}{ Unwanted Sexual Materials } \\
\hline \multirow[t]{2}{*}{ Supervisor } & x87b78 & 0.934 & 0.869 & x94b87 & 0.908 & 0.771 \\
\hline & $\mathrm{x} 78 \mathrm{~b} 87$ & 0.894 & 0.765 & x87b94 & 0.936 & 0.877 \\
\hline \multirow[t]{2}{*}{ Co-Worker } & $\mathrm{x} 87 \mathrm{~b} 78$ & 0.875 & 0.752 & x94b87 & 0.849 & 0.667 \\
\hline & x78b87 & 0.838 & 0.673 & x87b94 & 0.895 & 0.817 \\
\hline \multicolumn{7}{|c|}{ Unwanted Pressure for Sexual Favors } \\
\hline \multirow[t]{2}{*}{ Supervisor } & $\mathrm{x} 87 \mathrm{~b} 78$ & 0.916 & 0.841 & x94b87 & 0.992 & 0.955 \\
\hline & x78b 87 & 0.985 & 0.961 & x87b94 & 0.990 & 0.973 \\
\hline \multirow[t]{2}{*}{ Co-Worker } & $\mathrm{x} 87 \mathrm{~b} 78$ & 0.809 & 0.646 & x94b87 & 0.980 & 0.889 \\
\hline & $\mathrm{x} 78 \mathrm{~b} 87$ & 0.974 & 0.905 & x87b94 & 0.980 & 0.929 \\
\hline \multicolumn{7}{|c|}{ Unwanted Deliberate Touching } \\
\hline \multirow[t]{2}{*}{ Supervisor } & x87b78 & 0.904 & 0.830 & x94b87 & 0.956 & 0.893 \\
\hline & $\mathrm{x} 78 \mathrm{~b} 87$ & 0.945 & 0.891 & x87b94 & 0.977 & 0.929 \\
\hline \multirow[t]{2}{*}{ Co-Worker } & $\mathrm{x} 87 \mathrm{~b} 78$ & 0.836 & 0.688 & $\mathrm{x} 94 \mathrm{~b} 87$ & 0.924 & 0.823 \\
\hline & $\mathrm{x} 78 \mathrm{~b} 87$ & 0.917 & 0.825 & $\mathrm{x} 87 \mathrm{~b} 94$ & 0.952 & 0.895 \\
\hline \multicolumn{7}{|c|}{ Unwanted Pressure for Dates } \\
\hline \multirow[t]{2}{*}{ Supervisor } & $\mathrm{x} 87 \mathrm{~b} 78$ & 0.776 & 0.758 & x94b87 & 0.878 & 0.816 \\
\hline & $\mathrm{x} 78 \mathrm{~b} 87$ & 0.854 & 0.813 & x87b94 & 0.890 & 0.855 \\
\hline \multirow[t]{3}{*}{ Co-Worker } & $\mathrm{x} 87 \mathrm{~b} 78$ & 0.649 & 0.586 & x94b87 & 0.760 & 0.639 \\
\hline & $\mathrm{x} 78 \mathrm{~b} 87$ & 0.753 & 0.666 & x87b94 & 0.833 & 0.748 \\
\hline & & anel B: & asures 0 & ted Sexua & Harassn & \\
\hline \multicolumn{7}{|l|}{ Any Behavior } \\
\hline & x $87 \mathrm{~b} 78$ & 0.408 & 0.139 & x94b87 & 0.396 & 0.149 \\
\hline & $\mathrm{x} 78 \mathrm{~b} 87$ & 0.411 & 0.141 & x87b94 & 0.450 & 0.187 \\
\hline \multicolumn{7}{|c|}{ Unwanted Sexual Attention } \\
\hline & x87b78 & 0.303 & 0.080 & x94b87 & 0.272 & 0.100 \\
\hline & $\mathrm{x} 78 \mathrm{~b} 87$ & 0.298 & 0.087 & x87b94 & 0.292 & 0.096 \\
\hline
\end{tabular}

Notes: Sampling weights used. Separate probits estimated for each year. Probits include controls for age, education, marital status, occupation, pay grade, and gender of one's supervisor.

\section{Determinants of Views toward Unwanted Pressure for Sexual Favors and Dates}

We begin by pooling our data across years and estimating the following model of the determinants of views toward sexual harassment:

$$
\begin{gathered}
\operatorname{Pr}\left(Y_{i t}^{j}=1\right)=\operatorname{Pr}\left(X_{i} \beta+X_{i} D_{87} \gamma_{87}\right. \\
\left.+X_{i} D_{94} \gamma_{94}+\varepsilon_{i t}>0\right) \\
=\Phi\left(X_{i} \beta+X_{i} D_{87} \gamma_{87}+X_{i} D_{94} \gamma_{94}\right)
\end{gathered}
$$




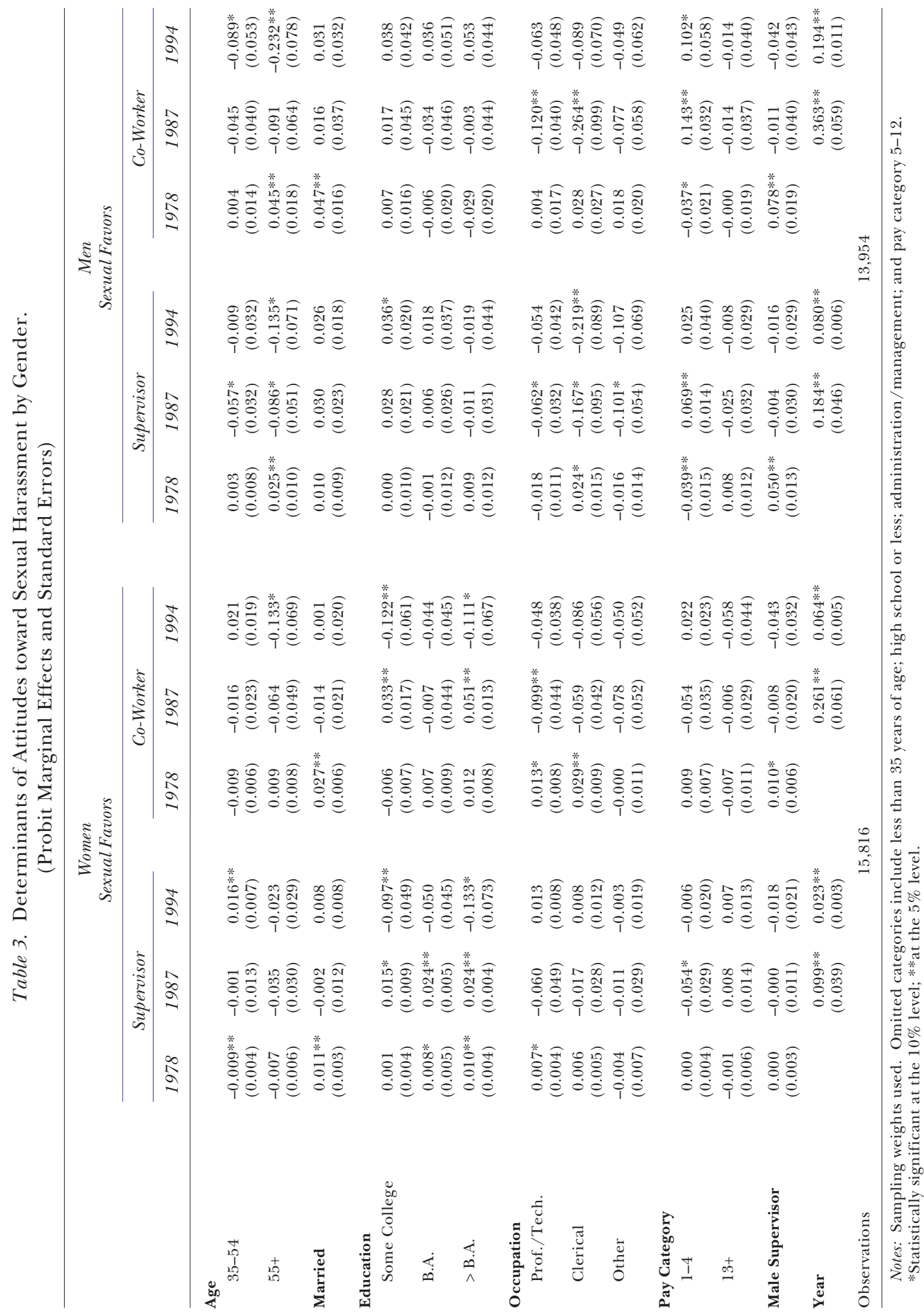




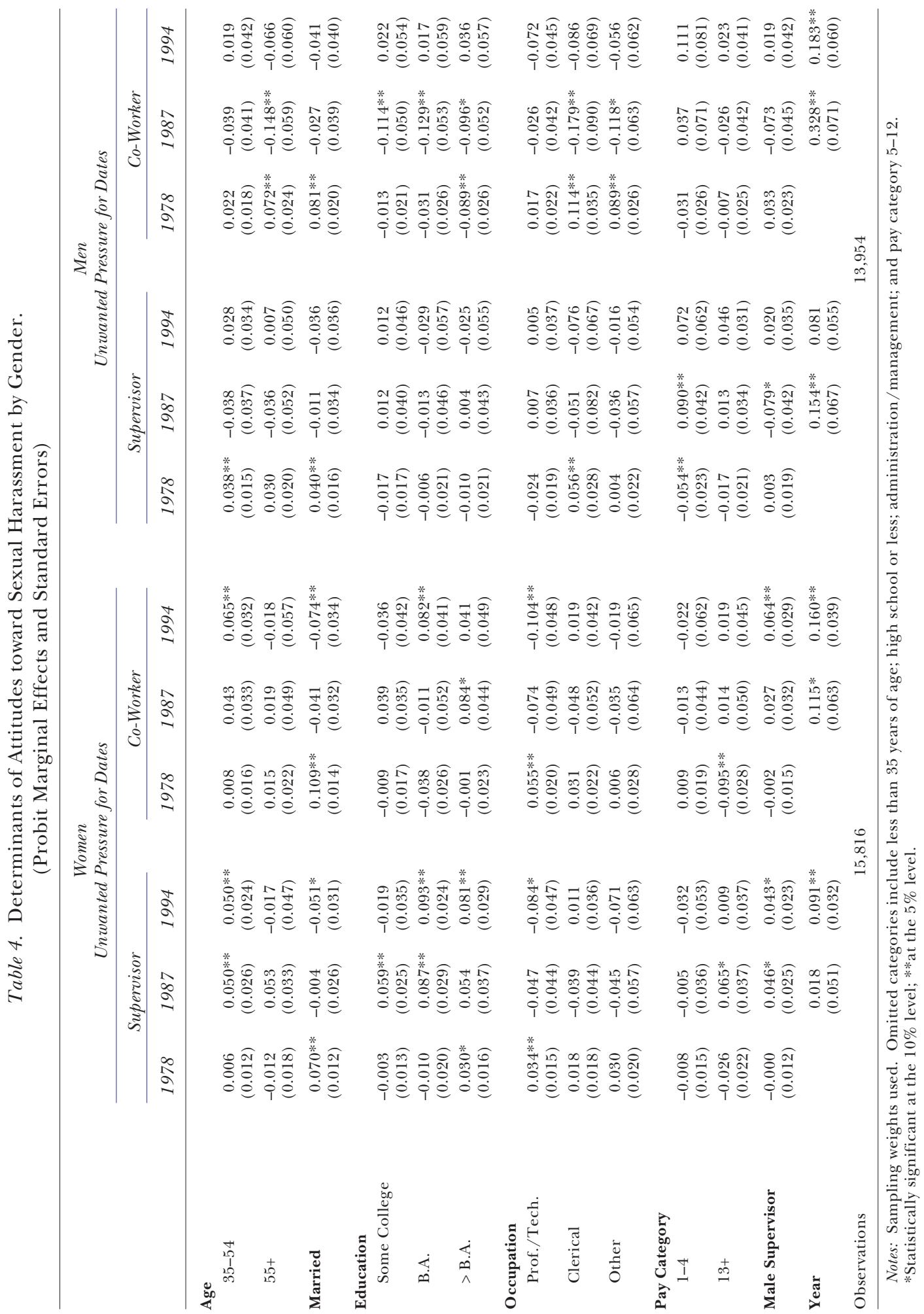


where $D_{87}$ and $D_{94}$ are dummy variables that equal one for 1987 and 1994 observations, respectively. Results (probit marginal effects and standard errors) for attitudes toward unwanted pressure for sexual favors and dates are presented in Tables 3 and $4 .^{16}$ Marginal effects for the base year (1978) are presented in the first column in each panel, while results in the second $\left(\gamma_{87}\right)$ and third $\left(\gamma_{94}\right)$ columns reflect changes between the reference and base years. ${ }^{17}$

In general, in 1978 there was no relationship between a woman's age and the probability that she would view unwanted pressure from a colleague or a supervisor for dates or sexual favors as sexual harassment. A clear age pattern in 1978 does emerge for men, however, with older men (aged 55 plus) significantly more likely than younger men (aged less than 35) to respond that pressure for sexual favors and unwanted pressure for dates were forms of sexual harassment. Over time, older women (men) employed in the federal government have become relatively more likely (less likely) to label unwanted pressure for sexual favors and dates as a form of sexual harassment, although these patterns are more evident in women's views of unwanted pressure for dates and in men's views of unwanted pressure for sexual favors.

Married women are more likely than unmarried women to report incidents of unwanted gender-related behavior on the job (Antecol and Cobb-Clark 2001; USMSPB 1981, 1988, 1995), and married individuals-both men and women-employed in the U.S. federal government are in general more likely to label unwanted pressure for dates and sexual favors as sexual harass-

\footnotetext{
${ }^{16}$ Given space constraints, we have chosen to focus our attention on these forms of unwanted sexual behavior. All other results are available upon request.

${ }^{17}$ Results presented in Tables 3 and 4 do not include controls for U.S. government agency. We also estimated a version of equation (3) including agency dummy variables and found the results to be very similar. Results controlling for agency effects are also available upon request.
}

ment than are unmarried individuals. This suggests that married individuals are more sensitive to incidents of unwanted sexual behavior in the workplace. Interestingly, this relationship was remarkably stable across the 16-year time period considered in this study.

Moreover, a worker's education level is related to views about sexual harassmentparticularly for women. In 1978 women with more than a B.A. were more likely than women without any college education to consider pressure from a supervisor for dates and sexual favors to be sexual harassment, while men with more than a B.A. were less likely than men without any college education to view a co-worker's pressure for dates as a form of sexual harassment. This "education gap" in women's views about unwanted sexual behavior continued to widen over time. The exception is that the education gap in women's attitudes toward pressure for sexual favors declined between 1987 and 1994. Interestingly, a similar result holds for men's views about a co-worker's unwanted pressure for dates. In 1987, educated men were significantly less likely than less educated men to see this as a form of sexual harassment. ${ }^{18}$

Finally, the year effects in Tables 3 and 4 reflect changes (relative to the base year 1978) in the probability that the reference individual-a single individual less than 35 years old with a high school degree, employed as an administrator/manager in pay grade 5-12, and overseen by a female supervisor-considered unwanted sexual behavior on the job to be sexual harassment. In general, the results indicate a growing tendency of workers to label such behavior as sexual harassment. The exception is in women's attitudes toward unwanted pressure for dates.

\footnotetext{
${ }^{18}$ Views about which behaviors constitute sexual harassment depend to a degree on the nature of a worker's job (occupation, job type, and gender of one's supervisor) even after controlling for demographic and human capital characteristics (see Tables 3 and 4).
} 


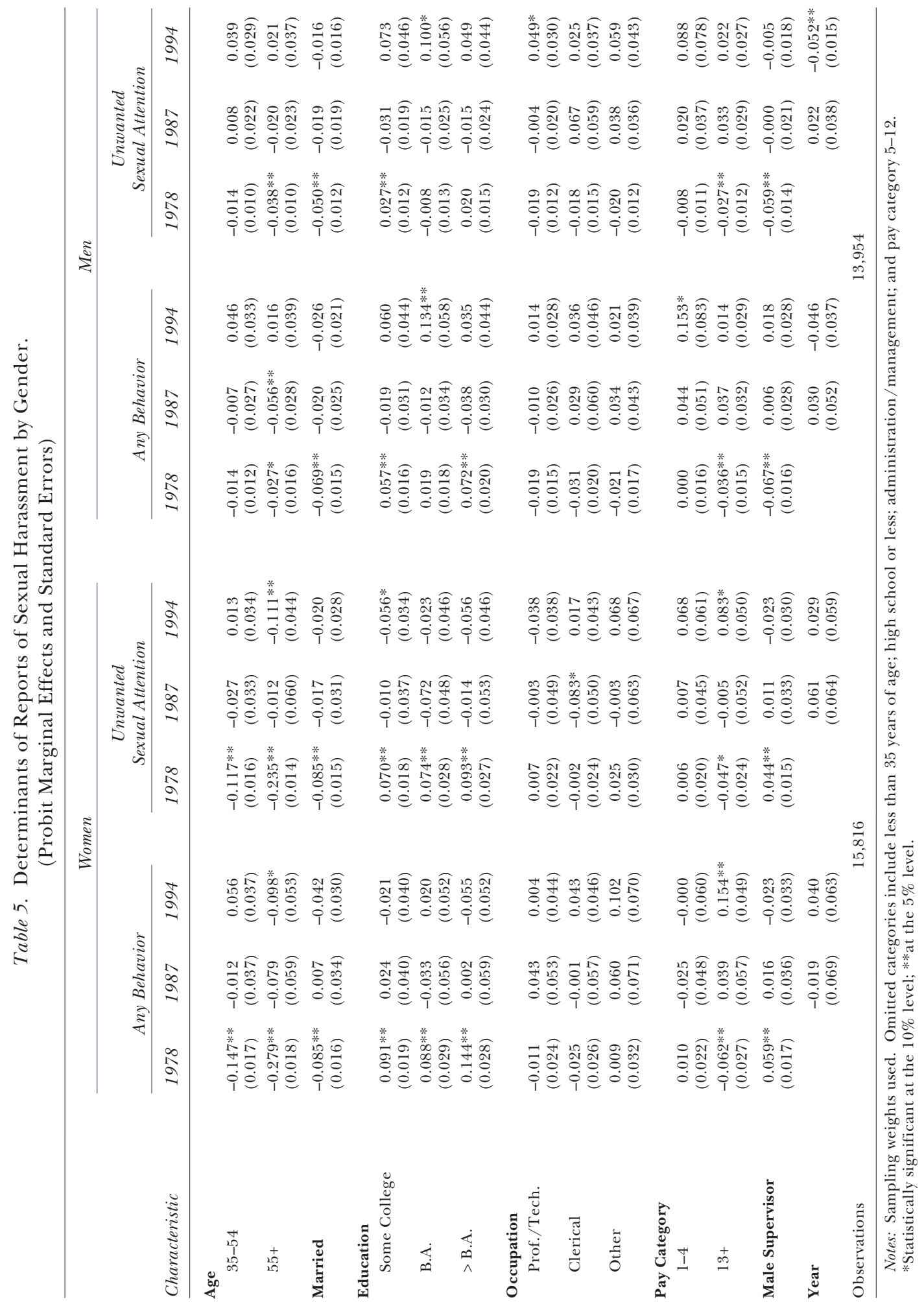




\section{Incidents of Unwanted Sexual Behavior}

To assess how the factors influencing reported unwanted sexual behavior have changed over time, we also estimate equation (3) for our two indicator variables"any unwanted behavior" and "unwanted sexual attention"-which measure the incidence in the previous 24 months of unwanted sexual behaviors among federal government employees. Results (probit marginal effects and standard errors) are shown in Table $5 .^{19}$

In 1978, older workers were less likely to report experiencing any unwanted sexual behavior or unwanted sexual attention than were younger workers, although the magnitude of the gap is larger for women. Over time, the relative gap in older workers' reports of unwanted sexual behavior grew, so that by 1994 workers over the age of $55-$ particularly women-were much less likely than younger workers to experience unwanted behavior on the job. Consistent with previous evidence (Antecol and CobbClark 2001; USMSPB 1981, 1988, 1995), married men and women were between 5.0 and 8.5 percentage points less likely in 1978 to report experiencing some form of unwanted sexual behavior than were unmarried men and women, and this relationship was stable over the 1978-94 period.

Individuals employed by the U.S. federal government in 1978 were much more likely to report experiencing any unwanted sexual behavior on the job if they had some college education, although the magnitude of the effect is substantially larger for educated women than for educated men. Similarly, a positive and statistically significant relationship between a female employee's education and her tendency to report being subjected to unwanted pressure for sexual attention is found; however, no such pattern is found for men. While the education patterns were remarkably stable between 1978 and 1994 for women, there was a substantial increase between 1978 and

\footnotetext{
${ }^{19}$ Results controlling for government agency are similar and are available upon request.
}

1994 in the probability that men with a B.A only (relative to men without any college education) reported experiencing unwanted sexual behavior generally and unwanted pressure for sexual attention specifically..$^{20}$ Finally, except for male reports of unwanted sexual attention, the year effects in Table 5 indicate that there was no overall time trend in reports of unwanted sexual behavior.

\section{Changes in the Qualitative Nature of Unwanted Sexual Behavior at Work}

The trends in sexual harassment discussed above raise questions regarding the qualitative nature of sexual harassment. Specifically, has the frequency, duration, or severity of harassment changed in a way that is not reflected in the overall incidence of sexual harassment? To address this question, we use our USMSPB data to study the circumstances surrounding reports of unwanted sexual behavior. Specifically, employees reporting one or more incidents of unwanted sexual behavior were then asked a series of follow-up questions about the specific behaviors they experienced, the characteristics of their harasser, and the consequences of their experience. Individuals were also asked whether they had filed a formal complaint. Mean responses to these questions about the qualitative nature of unwanted sexual behavior are reported in Table $6 .{ }^{21}$

The nature of sexual harassment in public-sector employment appears to have changed, with a decline in the incidence of unwanted sexual attention and an increase in crude and offensive behavior. Relative to harassed women in 1978 , women report-

\footnotetext{
${ }^{20}$ Unwanted sexual behavior is also related to the nature of one's job (occupation, job type, and gender of one's supervisor) even after controlling for demographic and human capital characteristics (see Table 5).

${ }^{21}$ The sample includes men and women reporting one or more of the unwanted sexual behaviors outlined in Table 1. The sample sizes for particular data items are given in the final row of Table 6 .
} 
ing some form of unwanted sexual behavior in 1994 were less likely to say that they had experienced pressure for sexual favors, pressure for dates, and deliberate touching, and more likely to say that they had been subjected to unwanted sexual material and remarks. Men were also less likely to report that their experiences included pressure for sexual favors, and more likely to report being the focus of unwanted sexual remarks in 1994 than in 1978though the change was statistically significant only between 1987 and 1994 .

The gender distribution of alleged harassers is unchanged, with more than $97 \%$ of harassed women reporting that their harasser was male. Interestingly, approximately $70 \%$ of men reported being harassed by a woman. Still, there was a statistically significant fall in the probability that a woman's harasser was either her immediate supervisor or another higher-level supervisor, and a statistically significant increase in the probability that a woman reported being harassed by a co-worker.

The frequency of reported harassment was lower in 1994 than in 1978. For both women and men there was a large and statistically significant increase in the probability-from $25.4 \%$ to $34.0 \%$ for women, and from $31.5 \%$ to $49.4 \%$ for men-that the harassment occurred only once, and a statistically significant fall in the probability that the harassment occurred every day or every few days. Still, the duration of harassment increasedat least for women. Women were also more likely to feel that being harassed had hurt their productivity in 1994 than in 1987 , while the proportion of harassed women filing formal complaints-though very low-more than doubled from $2.5 \%$ to $5.9 \%$ over the period.

\section{Discussion and Directions for Future Research}

Federal government employees' definition of sexual harassment broadened rapidly between 1978 and 1994. This was a period in which large numbers of women entered federal service-many in traditionally male-dominated occupations-leading to a gender integration of occupations and a narrowing of the gender-wage gap that was more rapid in federal employment than in the labor market generally (Lewis 1996). In spite of this, the increased willingness to label certain behaviors as sexual harassment was not driven by a change in women's employment patterns, but rather stemmed from an altered view (conditional on characteristics) of what in fact constitutes sexual harassment.

This structural change affected men's and women's views quite differently, however. Women remained much more likely than men to see sexual behavior on the job as sexually harassing. Such gender differences have important implications for U.S. employers as the legal system increasingly relies on what a reasonable woman (rather than a reasonable person) would find unwelcome when making determinations in sexual harassment cases (Prior et al. 1997; Fitzgerald and Shullman 1993).

While the decomposition methodology allows us to assess the relative importance of structural change, it leaves us speculating about the processes that may have brought it about. Two issues may be particularly relevant here. First, awareness of sexual harassment as an important social issue has grown as the result of several well-publicized court cases (Prior et al. 1997). Second, many firms have responded by implementing formal policies, grievance procedures, and training programs directed toward reducing sexual harassment. Little is known about the impact of such initiatives (Bingham and Scherer 2001; Fitzgerald and Shullman 1993; USMSPB 1995), ${ }^{22}$ though workers' awareness of and attitudes toward sexual harassment do appear to be influenced by training (Antecol and Cobb-Clark 2003 and the references

${ }^{22}$ These interventions have not as yet been evaluated, and Fitzgerald and Shullman (1993) pointed to this as a "glaring omission" in the sexual harassment research agenda. 
Table 6. Circumstances Surrounding Reported Sexual Harassment. ${ }^{a}$

\begin{tabular}{|c|c|c|c|c|c|c|}
\hline & \multicolumn{3}{|c|}{ Women } & \multicolumn{3}{|c|}{ Men } \\
\hline & 1978 & 1987 & 1994 & 1978 & 1987 & 1994 \\
\hline \multicolumn{7}{|l|}{ Behavior(s) in the Situation ${ }^{\mathrm{b}}$} \\
\hline $\begin{array}{l}\text { Actual/Attempted Rape or Sexual } \\
\text { Assault } \\
\text { Unwanted Pressure for Sexual Favors } \\
\text { Unwanted Deliberate Touching } \\
\text { Unwanted Sexual Gestures } \\
\text { Unwanted Sexual Materials } \\
\text { Unwanted Pressure for Dates } \\
\text { Unwanted Sexual Remarks }\end{array}$ & $\begin{array}{l}0.018 \\
0.155 \\
0.571 \\
0.493 \\
0.120 \\
0.245 \\
0.634\end{array}$ & $\begin{array}{l}0.019 \\
0.138 \\
0.569 \\
0.462 \\
0.151 \\
0.200 \\
0.631\end{array}$ & $\begin{array}{l}0.016 \\
0.079^{\mathrm{d}, \mathrm{e}} \\
0.488^{\mathrm{d}, \mathrm{e}} \\
0.497^{\mathrm{e}} \\
0.161^{\mathrm{e}} \\
0.193^{\mathrm{e}} \\
0.691^{\mathrm{e}}\end{array}$ & $\begin{array}{l}0.014 \\
0.119 \\
0.443 \\
0.416 \\
0.131 \\
0.145 \\
0.581\end{array}$ & $\begin{array}{l}0.022 \\
0.180 \\
0.454 \\
0.378 \\
0.161 \\
0.197 \\
0.508\end{array}$ & $\begin{array}{l}0.008 \\
0.079^{\mathrm{d}} \\
0.408 \\
0.400 \\
0.143 \\
0.153 \\
0.622^{\mathrm{d}}\end{array}$ \\
\hline \multicolumn{7}{|l|}{ Who Caused the Situation ${ }^{\mathrm{b}}$} \\
\hline $\begin{array}{l}\text { Immediate Supervisor } \\
\text { Other Higher Level Supervisor (s) } \\
\text { Co-Worker(s) } \\
\text { Subordinates } \\
\text { Other Employees } \\
\text { Other/Unknown }\end{array}$ & $\begin{array}{l}0.181 \\
0.210 \\
0.336 \\
0.033 \\
0.389 \\
0.057\end{array}$ & $\begin{array}{l}0.122^{\mathrm{c}} \\
0.197^{\mathrm{c}} \\
0.411^{\mathrm{c}} \\
0.021 \\
0.378 \\
0.094^{\mathrm{c}}\end{array}$ & $\begin{array}{l}0.121^{\mathrm{e}} \\
0.171^{\mathrm{e}} \\
0.458^{\mathrm{e}} \\
0.035 \\
0.389 \\
0.065\end{array}$ & $\begin{array}{l}0.073 \\
0.074 \\
0.423 \\
0.162 \\
0.401 \\
0.043\end{array}$ & $\begin{array}{l}0.116 \\
0.099 \\
0.475 \\
0.107 \\
0.389 \\
0.098\end{array}$ & $\begin{array}{l}0.053 \\
0.092 \\
0.497 \\
0.105 \\
0.355 \\
0.062\end{array}$ \\
\hline $\begin{array}{c}\text { Gender of Harasser } \\
\text { Male Harasser } \\
\text { Female Harasser }\end{array}$ & $\begin{array}{l}0.972 \\
0.028\end{array}$ & & $\begin{array}{l}0.984 \\
0.016\end{array}$ & $\begin{array}{l}0.278 \\
0.722\end{array}$ & & $\begin{array}{l}0.301 \\
0.699\end{array}$ \\
\hline $\begin{array}{l}\text { Frequency of Harassment } \\
\text { Once } \\
\text { Once a Month or Less } \\
\text { 2-4 Times per Month } \\
\text { Every Few Days } \\
\text { Every Day }\end{array}$ & $\begin{array}{l}0.254 \\
0.277 \\
0.209 \\
0.216 \\
0.043\end{array}$ & $\begin{array}{l}0.327^{\mathrm{c}} \\
0.205^{\mathrm{c}} \\
0.263^{\mathrm{c}} \\
0.154^{\mathrm{c}} \\
0.051\end{array}$ & $\begin{array}{l}0.340^{\mathrm{e}} \\
0.245^{\mathrm{e}} \\
0.269^{\mathrm{e}} \\
0.132^{\mathrm{e}} \\
0.014^{\mathrm{d}, \mathrm{e}}\end{array}$ & $\begin{array}{l}0.315 \\
0.353 \\
0.137 \\
0.154 \\
0.041\end{array}$ & $\begin{array}{l}0.347 \\
0.213^{c} \\
0.226^{c} \\
0.183 \\
0.031\end{array}$ & $\begin{array}{l}0.494^{\mathrm{d}, \mathrm{e}} \\
0.266^{\mathrm{e}} \\
0.154 \\
0.066^{\mathrm{d}, \mathrm{e}} \\
0.019\end{array}$ \\
\hline $\begin{array}{l}\text { Duration of Harassment } \\
\text { Less Than One Week } \\
\text { Several Weeks } \\
\text { 1-6 Months } \\
\text { More Than } 6 \text { Months }\end{array}$ & $\begin{array}{l}0.311 \\
0.184 \\
0.228 \\
0.277\end{array}$ & $\begin{array}{l}0.370^{\mathrm{c}} \\
0.113^{\mathrm{c}} \\
0.239 \\
0.278\end{array}$ & $\begin{array}{l}0.331 \\
0.107^{\mathrm{e}} \\
0.230 \\
0.332^{\mathrm{e}}\end{array}$ & $\begin{array}{l}0.395 \\
0.182 \\
0.202 \\
0.222\end{array}$ & $\begin{array}{l}0.378 \\
0.095^{c} \\
0.225 \\
0.302\end{array}$ & $\begin{array}{l}0.456 \\
0.084^{\mathrm{e}} \\
0.215 \\
0.245\end{array}$ \\
\hline $\begin{array}{l}\text { Harassment Had an Adverse Effect On } \\
\text { Feelings about Work } \\
\text { Emotional of Physical Condition } \\
\text { Ability to Work with Others on the } \\
\text { Job } \\
\text { Quality of Work } \\
\text { Quantity of Work } \\
\text { Time and Attendance at Work }\end{array}$ & $\begin{array}{l}0.353 \\
0.324 \\
\\
0.143 \\
0.087 \\
0.097 \\
0.106\end{array}$ & $\begin{array}{l}0.313 \\
0.319 \\
0.132 \\
0.076 \\
0.099 \\
0.120\end{array}$ & & $\begin{array}{l}0.179 \\
0.194 \\
0.145 \\
0.081 \\
0.091 \\
0.076\end{array}$ & $\begin{array}{l}0.265 \\
0.231 \\
\\
0.194 \\
0.101 \\
0.106 \\
0.128\end{array}$ & \\
\hline Harassment Hurt Productivity & & 0.198 & $0.263^{\mathrm{d}}$ & & 0.172 & 0.192 \\
\hline Filed a Formal Complaint & 0.025 & 0.048 & $0.059^{\mathrm{e}}$ & 0.010 & 0.055 & 0.034 \\
\hline Observations & $2,283-2,739$ & $1,321-1,253$ & $1,307-1,281$ & $773-640$ & $342-322$ & $389-375$ \\
\hline
\end{tabular}

Sampling Weights Used.

a Refers to the one uninvited sexual experience that is either the most recent or that had the greatest effect on the individual.

${ }^{\mathrm{b} A s}$ mulitple responses were allowed, the columns do not sum to one.

${ }^{c, d, e}$ Refers to statistically significant differences between the means in 1978 vs. 1987, 1987 vs. 1994, and 1978 vs. 1994, respectively, at the $5 \%$ level.

therein). Our data, however, do not allow us to control for either of these factors, and their effect would be reflected in the analysis through the coefficientsthat is, in structural change.

To the extent that a more expansive 
definition of sexual harassment is associated with an increased awareness of and sensitivity to the issue, this did not result in a reduction in the reported incidence of unwanted sexual behavior. The rate at which government employees reported experiencing unwanted sexual behavior was essentially unchanged between 1978 and 1987, and rose slightly between 1987 and 1994. Some have speculated that perhaps a broader definition of sexual harassment and increased awareness in fact contributed to this increase in the reported incidence of unwanted sexual behavior in federal employment (USMSPB 1995). The link between worker attitudes and worker behavior is far from established, however, and more research along these lines would be most useful.

Though the incidence of unwanted sexual behavior was relatively constant between 1978 and 1994, there were important changes in the qualitative nature of harassment. More severe forms of harassment (for example, unwanted sexual attention from supervisors) became less common, and there was an increased tendency for harassment to occur only once, suggesting that on average reported sexual harassment was perhaps less severe in 1994 than in 1978. At the same time, the duration of harassment was somewhat longer, and more women reported suffering a loss of productivity as a result of their harassment experience. Perhaps women had become more sensitive to the productivity losses associated with sexual harassment. The effect of these conflicting trends on costs is unclear, but if a more expansive definition of sexual harassment leads to more court cases-even in the face of an unchanged incidence-we would certainly expect the legal costs associated with sexual harassment to increase.

Finally, we can only speculate on how relevant these results based on public-sector employees are for the private sector. On the one hand, it is often thought that the federal government may be in a better position to enforce labor standards gener- ally, including perhaps providing a nonharassing work environment. ${ }^{23}$ Still, a review of the literature suggests that this has not resulted in substantially lower levels of harassment within the federal government. Thus, an analysis of the trends in unwelcome sexual behavior-such as this one-across a wide range of employment situations within the public sector is likely to have implications for private sector employment as well.

\section{Conclusions}

How has the nature of employment-related sexual harassment changed? This paper addresses this question by using data spanning a fifteen-year period to assess employees' views toward and experiences of unwanted sexual behavior. Whereas much of the existing sexual harassment literature is based on relatively small and select samples of workers, this paper is unique in analyzing a large number of public-sector workers employed in a range of occupations across all agencies of the U.S. federal government.

We find that the willingness of federal employees to define employment-related, unwanted sexual behavior to be sexual harassment increased dramatically between 1978 and 1994 as a result of structural changes in views of what constitutes sexual harassment. In the face of a rapidly expanding definition of what it means to be sexually harassed, it is surprising, then, that the reported incidence of unwanted sexual behavior on the job changed very little between 1978 and 1994. Women's reports of unwanted sexual behavior on the job increased by 4.4 percentage points, while men's reports increased by 5.6 percentage points over those years.

The qualitative nature of harassment in public-sector employment also changed

\footnotetext{
${ }^{23}$ For example, federal affirmative action regulations led to a higher rate of employment of blacks by federal contractors than by non-contractors (Leonard 1990).
} 
between 1978 and 1994. Sexual harassment in the early 1990s was more likely to involve crude or offensive behavior and originate with co-workers, and less likely to involve unwanted sexual attention and immediate or higher level supervisors. There was also an increased tendency for harassment to occur only once, though the duration of harassment was somewhat longer and more women reported suffering a loss of productivity as a result of their harassment experience. 


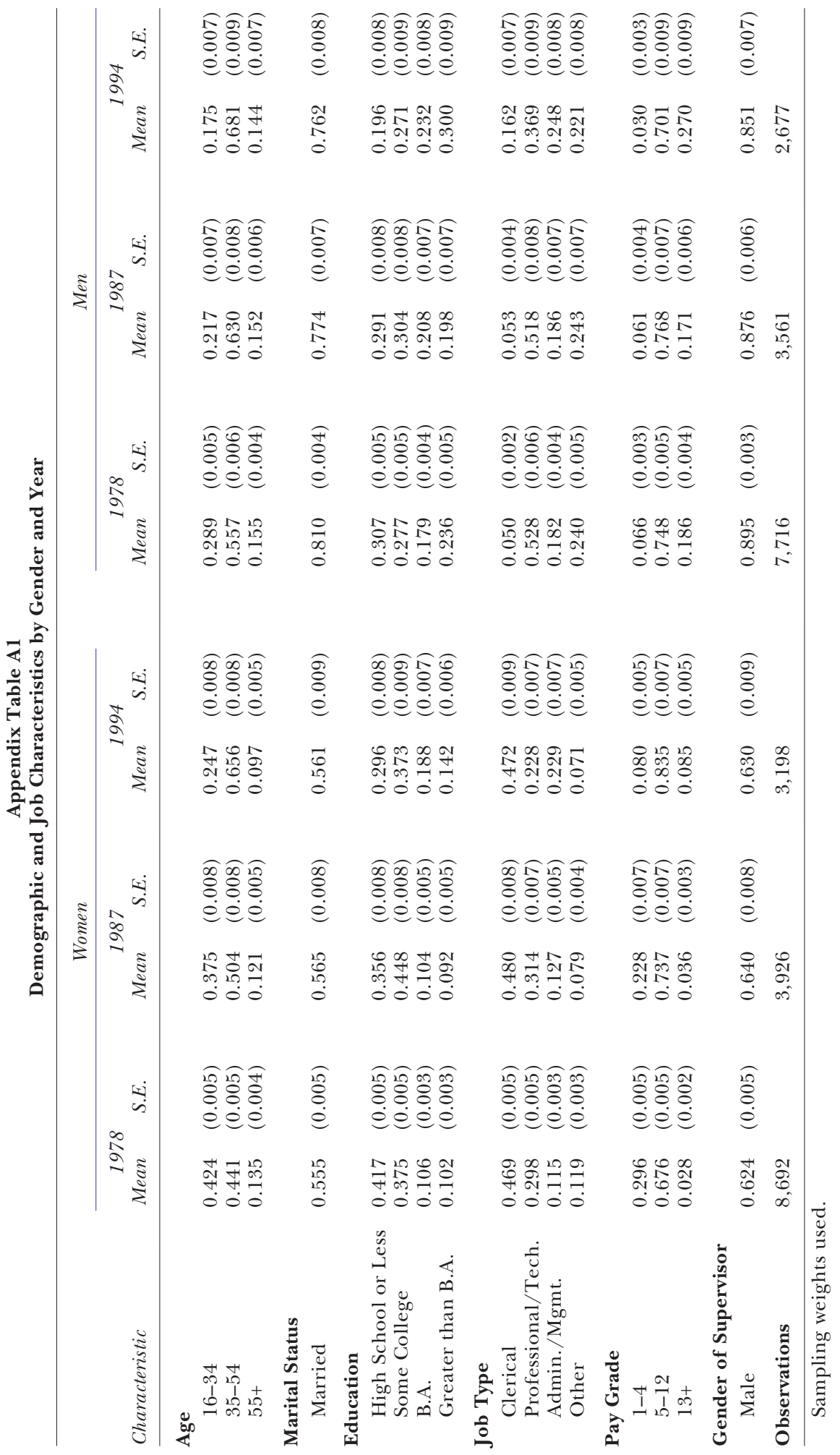




\section{REFERENCES}

Antecol, Heather, and Deborah Cobb-Clark. 2001 "Men, Women, and Sexual Harassment in the U.S. Military." Gender Issues, Vol. 19, No. 1 (Winter), pp. 3-18.

2002. "Sexual Harassment of Female ActiveDuty Personnel: The Effect on Job Satisfaction and Intentions to Remain in the Military." IZA Discussion Paper, No. 379.

2003. "Does Sexual Harassment Training Change Attitudes? A View from the Federal Level." Social Science Quarterly, Vol. 84, No. 4 (December), pp. 826-42.

Basu, Kaushik. 2002. "Sexual Harassment in the Workplace: An Economic Analysis with Implications for Worker Rights and Labor Standards Policy." Unpublished paper, Massachusetts Institute of Technology.

Bingham, Shereen G., and Lisa L. Scherer. 2001. "The Unexpected Effects of a Sexual Harassment Educational Program." Journal of Applied Behaviorial Science, Vol. 37, No. 2 (June), pp. 125-53.

Doiron, Denise J., and W. Craig Riddell. 1994. "The Impact of Unionization on Male-Female Earnings Differences in Canada." Journal of Human Resources, Vol. 29, No. 2 (Spring), pp. 504-34.

Fitzgerald, Louise F., Fritz Drasgow, Charles L. Hulin, Michele J. Gelfand, and Vicki J. Magley. 1997. "Antecedents and Consequence of Sexual Harassment in Organizations: A Test of an Integrated Model." Journal of Applied Psychology, Vol. 82, No. 3 (August), pp. 578-89.

Fitzgerald, Louise F., Fritz Drasgow, and Vicki J. Magley. 1999b. "Sexual Harassment in the Armed Forces: A Test of an Integrated Model." Military Psychology, Vol. 11, No. 3, pp. 329-43.

Fitzgerald, Louise F., Vicki J. Magley, Fritz Drasgow, and Craig R. Waldo. 1999a. "Measuring Sexual Harassment in the Military: The Sexual Experiences Questionnaire (SEQ-DoD).” Military Psychology, Vol. 11, No. 3, pp. 247-63.

Fitzgerald, Louise F., and Alayne J. Ormerod. 1993. "Breaking Silence: The Sexual Harassment of Women in Academia and the Workplace." In Florence L. Denmark and Michele A. Paludi, eds., Psychology of Women: A Handbook of Issues and Theories. Westport, Conn.: Greenwood Press, pp. 553-82.

Fitzgerald, Louise F., and S. L. Shullman. 1993. "Sexual Harassment: A Research Analysis and Agenda for the 1990s." Journal of Vocational Behavior, Vol. 42, No. 1 (February), pp. 5-27.

Foulis, Danielle, and Marita McCabe. 1997. "Sexual Harassment: Factors Affecting Attitudes and Perceptions." Sex Roles, Vol. 37, No. 9/10 (November), pp. 773-98.

International Labour Office (ILO). 1992. "Combating Sexual Harassment at Work." Conditions of Work Digest, Vol. 11, No. 1, Geneva.

Johnson, Holly. 1994. "Work-Related Sexual Harassment." Perspectives, Statistics Canada, Catalogue, 75-001E (Winter), pp. 9-12.

Laband, David N., and Bernard F. Lentz. 1998. "The
Effects of Sexual Harassment on Job Satisfaction, Earnings, and Turnover among Female Lawyers." Industrial and Labor Relations Review, Vol. 51, No. 4 (July), pp. 594-607.

Leonard, Jonathan S. 1990. "The Impact of Affirmative Action Regulation and Equal Employment Law on Black Employment." Journal of Economic Perspectives, Vol. 4, No. 4 (Autumn), pp. 47-63.

Lewis, Gregory B. 1996. "Gender Integration of Occupations in the Federal Civil Service: Extent and Effects on Male-Female Earnings." Industrial and Labor Relations Review, Vol. 49, No. 3 (April), pp. 472-83.

Magley, Vicki J., Charles L. Hulin, Louise F. Fitzgerald, and Mary DeNardo. 1999. "Outcomes of SelfLabeling Sexual Harassment.” Journal of Applied Psychology, Vol. 84, No. 3 (June), pp. 390-402.

Marin, Amy J., and Rosanna E. Guadagno. 1999. "Perceptions of Sexual Harassment Victims as a Function of Labeling and Reporting." Sex Roles, Vol. 41, No. 11/12 (December), pp. 921-40.

Prior, John B., Julie Fitness, Claudio Hutz, Martin Kumpf, Karin Lubbert, Outi Pesonen, and Maureen Wang Erber. 1997. "Gender Differences in the Interpretation of Social-Sexual Behavior: A CrossCultural Perspective on Sexual Harassment." Journal of Cross-Cultural Psychology, Vol. 28, No. 5 (September), pp. 509-34.

Roscoe, B., J. S. Strouse, and M. P. Goodwin. 1994. "Sexual Harassment: Early Adolescents' Self-Reports of Experiences and Acceptance." Adolescence, Vol. 29, No. 115 (Fall), pp. 515-23.

Schneider, Kimberly T., Suzanne Swan, and Louise F. Fitzgerald. 1997. "Job-Related and Psychological Effects of Sexual Harassment in the Workplace: Empirical Evidence from Two Organizations." Journal of Applied Psychology, Vol. 82, No. 3 (August), pp. 401-515.

U.S. Bureau of the Census, Department of Commerce. 1980. Statistical Abstract of the United States: National Databook and Guide to Sources, $101^{\text {st }}$ edition. Washington, D.C.: Government Printing Office.

U.S. Merit Systems Protection Board (USMSPB). 1981. Sexual Harassment in the Federal Workplace: Is It a Problem? Washington, D.C.: Government Printing Office.

1988. Sexual Harassment in the Federal Workplace: An Update. Washington, D.C.: Government Printing Office.

1995. Sexual Harassment in the Federal Workplace: Trends, Progress, Continuing Challenges. Washington, D.C.: Government Printing Office.

U.S. Office of Personnel Management (USOPM). 1999. The Fact Book, 1999 Edition, Federal Civilian Work Force Statistics. Washington, D.C.: Government Printing Office, September.

Williams, Jill Hunter, Louise F. Fitzgerald, and Fritz Drasgow. 1999. "The Effects of Organizational Practices on Sexual Harassment and Individual Outcomes in the Military." Military Psychology, Vol. 11, No. 3, pp. 303-28. 